\title{
Clopidogrel reduced recurrent ischaemic events in patients with previous cardiac surgery more than aspirin
}

\author{
Bhatt DL, Chew DP, Hirsch AT, et al. Superiority of clopidogrel versus aspirin in patients with prior cardiac surgery. \\ Circulation 2001 Jan 23;103:363-8.
}
QUESTION: In patients with recent ischaemic stroke, recent myocardial infarction (MI), or peripheral arterial disease and previous cardiac surgery, is clopidogrel more effective than aspirin in reducing recurrent ischaemic events?

\begin{abstract}
Design
Subgroup analysis of a randomised \{allocation concealed*\}, blinded \{patients, clinicians, outcome assessors, and statisticians $\} \nmid{ }^{*}$ placebo controlled trial with 1-3 year follow up (mean 1.6 y) (Clopidogrel versus Aspirin in Patients at Risk of Ischemic Events [CAPRIE] study).
\end{abstract}

\section{Setting}

\{384 clinical centres in 16 countries $\} \uparrow$.

\section{Patients}

1480 patients (mean age 64 y, $84 \%$ men, $96 \%$ white) with recent stroke or MI or peripheral arterial disease who had also had cardiac surgery. Exclusion criteria were a history of bleeding disorders, uncontrolled hypertension, or severe renal or hepatic dysfunction. Follow up was $99.9 \%$.

\section{Intervention}

775 patients were allocated to clopidogrel, $75 \mathrm{mg}$ /day, and 705 to aspirin, $325 \mathrm{mg} /$ day.

\section{Main outcome measures}

Combined end point of vascular mortality, MI, and ischaemic stroke. Individual end points were also assessed.

\section{Main results}

Clopidogrel was associated with decreased annual rates of the primary end point (combined vascular death, MI, and stroke $)(\mathrm{p}=0.004)$, vascular death, MI, all cause hospitalisation (table), admission to hospital for ischaemia or bleeding $(p=0.02)$, and 3 other combined end points. The groups did not differ for annual rates of all cause mortality $(3.4 \%$ for aspirin $v 2.6 \%$ for clopidogrel, $\mathrm{p}=0.2)$ or stroke $(3.5 \%$ v $2.6 \%, \mathrm{p}=0.2)$.

\section{Conclusion}

Clopidogrel was more effective than aspirin for reducing recurrent ischaemic events in patients with recent stroke, recent myocardial infarction, or peripheral arterial disease who had also had previous cardiac surgery.

*See glossary.

†CAPRIE Steering Committee. Lancet 1996;348:1329_ 39.
Source of funding: no external funding.

For correspondence: Dr EJ Topol,

Department of

Cardiology, F25,

Cleveland Clinic

Foundation, 9500

Euclid Avenue,

Cleveland, $\mathrm{OH} 44195$,

USA.Fax +1216445

9595.
Clopidogrel $v$ aspirin for stroke, myocardial infarction, or peripheral arterial disease and previous cardiac surgerył

\begin{tabular}{lllll} 
Outcomes/year & Clopidogrel & Aspirin & RRR (95\% Cl) & NNT (CI) \\
Primary combined end point§ & $5.8 \%$ & $9.1 \%$ & $36 \%(13$ to 53$)$ & 30 (21 to 82$)$ \\
\hline Vascular death & $2.0 \%$ & $3.3 \%$ & $43 \%(5$ to 66$)$ & 71 (46 to 659$)$ \\
\hline Myocardial infarction & $2.4 \%$ & $3.9 \%$ & $39 \%(2$ to 62$)$ & 66 (41 to 1070$)$ \\
\hline Admission to hospital & $36 \%$ & $48 \%$ & $22 \%(9$ to 33$)$ & 10 (6 to 24$)$ \\
\hline
\end{tabular}

$\ddagger$ Abbreviations defined in glossary; RRR, NNT, and $\mathrm{Cl}$ provided by author.

\$Primary combined end point $=$ vascular death, myocardial infarction, and stroke

CAPRIE Steering Committee. A randomised, blinded, trial of clopidogrel versus aspirin in patients at risk of ischaemic events (CAPRIE). Lancet 1996;348:1329-39.

Mishkel GJ, Aguirre FV, Ligon RW, et al. Clopidogrel as adjunctive antiplatelet therapy during coronary stenting. J Am Coll Cardiol 1999;34:1884-90

3 Bennett CL, Connors JM, Carwile JM, et al. Thrombotic thrombocytopenic purpura associated with clopidogrel. N Engl J Med 1999;342:1773-7. 